\title{
Protesta democrática Democratic protest
}

\author{
Alicia García Ruiz \\ Universidad Carlos III de Madrid \\ alicgarc@hum.uc3m.es \\ Recibido / received: 16/07/2018 \\ Aceptado / accepted: 30/08/2018 \\ DOI: https://doi.org/10.20318/eunomia.2018.4349
}

\begin{abstract}
Resumen
En este trabajo se realiza un recorrido por la idea de protesta a lo largo de tres dimensiones. En primer lugar, se trata la relación de la protesta con la ley (incluyendo aquí el problema de la desobediencia civil y de la tensión entre legalidad y legitimidad). En segundo lugar, se aborda el papel político de la contestación social en el funcionamiento de las sociedades democráticas. En tercer lugar, se analiza el problema del populismo punitivo y las políticas represivas en el contexto de sociedades fuertemente marcadas por la desigualdad, la pobreza y la conflictividad social.
\end{abstract}

\section{Palabras clave}

Protesta, desobediencia, democracia, legalidad, legitimidad.

\begin{abstract}
In this article, the idea of protest is approached along three dimensions. First, it deals with the relationship between protest and law (with particular attention to the problem of civil disobedience and the tension between legality and legitimacy). Secondly, the political role of social contestation in the functioning of democratic societies is addressed. Finally, the problem of punitive populism and repressive policies is analyzed in the context of societies strongly marked by inequality, poverty and social conflict.
\end{abstract}

\section{Keywords}

Protest, disobedience, democracy, legality, legitimacy.

SUMARIO. 1. Consideraciones preliminares. 2. La protesta ante la ley.

3. Protesta y democracia. 4. Castigo o diálogo. Consideraciones finales.

\section{Fraternidad y la Revolución francesa}

La expresión de la discrepancia es un rasgo constitutivo de la forma de vida democrática, así como un derecho fundamental reconocido en un Estado democrático. Esta afirmación no se limita simplemente a describir que el desacuerdo sea una parte ineliminable en la dinámica de los sistemas políticos, una suerte de inevitable mal menor, sino que sostiene algo más penetrante. Afirma que la manifestación del desacuerdo es una condición necesaria para que podamos hablar de democracia: no hay democracia allí donde no puede haber protesta. Desde esta perspectiva, los fenómenos de protesta no aparecen como una desviación o 
disfuncionalidad de la dinámica normal de los sistemas políticos, sino como una dimensión central, constitutiva e irrenunciable del acuerdo democrático. Una dimensión sin cuya presencia no es posible la formación de voluntad popular desde unas condiciones de pluralidad política.

Ahora bien, que sea central no quiere decir que su relevancia resulte obvia. Alguien puede preguntar en buena lógica qué es, entonces, lo que separa el disentimiento institucionalmente canalizado -cuyo paradigma sería el debate parlamentario-, de la voz "protesta" aquí recogida, término que abarca tanto contestaciones extraparlamentarias como acciones incluso al borde mismo de la legalidad. $Y$ sobre todo podría preguntar por qué es necesario conceder este papel fundamental a la protesta si en teoría el derecho a la discrepancia como tal está ya garantizado en una democracia parlamentaria. Con el fin de adelantar un poco por dónde irá la respuesta debemos precisar que si distinguimos entre discrepancia institucionalmente canalizada y protesta es porque la voz "protesta" será abordada aquí precisamente desde aquellas circunstancias donde las condiciones ideales de diálogo democrático institucionalizado quiebran o fallan. El planteamiento que proponemos consiste en pensar los fenómenos de protesta en vista de esta posible quiebra o defecto del diálogo público y no sólo desde el caso de un quebrantamiento normativo.

Para ello adoptaremos, por utilizar una certera distinción de Norberto Bobbio, no la perspectiva del gobernante -ex parte principis- sino la de los gobernantes -ex parte populus. En otras palabras, en vez de centrarnos exclusivamente en los intentos de caracterizar si un conjunto de protestas encajan o no en unas condiciones o premisas normativas para una hipotética conversación democrática intentaremos reflexionar también qué ocurre cuando algunos de los participantes potenciales en esa conversación, o no están invitados, o bien carecen de las competencias comunicativas para participar en él.

Para ejemplificar el caso nos serviremos de una breve analogía planteada en el campo epistemológico por Wilfrid Sellars (Sellars, 1997: 76), autor que ha inspirado a pensadores como Richard Rorty, una imagen metafórica de la democracia entendida como una conversación o práctica social de justificación, más que de deducción normativa a partir de fundamentos. Para Sellars, "al caracterizar un episodio o un estado como relativo a un "conocer" no estamos proporcionando una descripción empírica de los mismos, sino situándolos en el espacio lógico de las razones, en el justificar y ser capaz de justificar lo que uno dice" (Sellars, 1997: 76). Como ha señalado Rorty, "la justificación no es cuestión de una relación especial entre ideas (y palabras) y objetos, sino de conversación, de práctica social" (Rorty, 2001: 161).

Si hay algo que se pide a la protesta desde numerosas aproximaciones teóricas es la de que "se justifique" o entre en ese espacio lógico de razones. La base de este requerimiento es la suposición de que debe haber "razones" (más concretamente, buenas razones) detrás de todo movimiento contestatario; razones que se pueden someter a examen, motivos que han de explicitarse, actos que deben justificarse para poder constituir una acción reconocida como simbólica y aceptablemente interpeladora. Sin duda, esta perspectiva es un avance respecto a la mera consideración de la protesta como algo tumultuario e irracional que es preciso reprimir o ignorar; equivale a adoptar un paradigma de conversación en lugar de uno de confrontación, entendiendo este diálogo como una labor epistemológica, un trabajo de justificación de disentimientos basado en el intercambio de argumentos. Sin embargo, la defensa de esta especie de "deber de justificación" no carece de aristas para abordar la cuestión de la protesta. 
El principal problema consiste en los límites que presenta para nuestros propósitos este paradigma de una conversación justificativa. Se puede ser parte integrante del espacio lógico de las razones sin poder llevar a efecto tal capacidad justificativa, bien porque no se posean las competencias comunicativas supuestas en un cierto espacio argumentativo o bien porque no se permita tal expresión en una situación de asimetría de poder. Cuando se dan, estas distorsiones impiden que funcione el supuesto de plena agencia política para quienes son instados a participar en la conversación democrática mediante el requerimiento de un "justifíquese....bajo estas reglas argumentativas". Si se da esta situación, la capacidad de respuesta democrática queda comprometida si sólo nos atenemos a considerar y requerir un "deber de justificación". Nuestra tesis, que desarrollaremos a lo largo de este trabajo, es que deberá entonces entrar en juego un opuesto (no contrario) "deber de escucha" institucional requerido en la dirección opuesta, o como diríamos en expresión de Bobbio, un deber planteado hacia los gobernantes, ante la parte principis. En la identificación de este deber, de esta responsabilidad de respuesta de la otra parte implicada, se juega también el carácter democrático del desafío contestatario y el retorno a un buen funcionamiento de las instituciones políticas. Pero, como se adivinará, es un camino lleno de ambivalencias y dilemas, marcado por la necesidad constante de aclaración acerca de los términos de la discusión misma, puesto que bajo el término protesta se agrupa una constelación semántica muy compleja que abarca términos como "resistencia", "contestación", "desobediencia civil", "rebelión", "revolución", "disidencia", etc. Nociones con una larga trayectoria histórica que en la actualidad se encuentran entremezclados en los discursos públicos y mediáticos, y que reclaman un proceso de clarificación doctrinal en el ámbito jurídico no siempre fácil ni exenta de influencias extrajurídicas.

En este trabajo trataremos de dilucidar por niveles el problema de la voz "protesta". En primer lugar, la consideraremos desde el punto de vista de la legalidad, señalando que el desafío que plantea excede los límites de funcionamiento del principio de legalidad y que aunque indudablemente exige pasar por la ardua cuestión de la desobediencia civil, el abanico de consideraciones que despliega no se detiene ahí ni se circunscribe sólo a ella. En segundo lugar, precisamente por este desbordamiento de la cuestión legal, abordaremos el papel político que tiene la protesta en el funcionamiento democrático. Finalmente, en función de los desarrollos de determinadas tendencias des-democratizadoras que han sido señaladas por diversos estudiosos, esbozaremos los peligros que acechan en el giro hacia una interpretación exclusiva de la protesta en clave punitiva, problema que es de esperar que sea agrave a la vista de la deriva de sociedades cada vez más marcadas por la desigualdad y las políticas del miedo. Esta interpretación punitiva se propone, esta vez sí, como lo contrario al "deber de escucha" que hemos presentado anteriormente.

\section{La protesta ante la ley}

Aunque el marco tan limitado de un trabajo de estas características no permite realizar un rastreo histórico adecuado del derecho de resistencia y del problema de la obediencia a la autoridad, que atravesaría desde la Edad Media la totalidad de los principales pensadores en materia jurídica y política -desde Grocio a Jefferson, pasando obviamente por Locke, Rousseau, Kant y otros muchos-, podemos señalar con Bobbio (2005: 277 y ss.) el desarrollo paulatino de un proceso gradual de constitucionalización del derecho de resistencia, que vendría a equilibrar la abundante justificación teórica del deber de obediencia y a trazar así una transición desde las concepciones tradicionales del poder como fuerza a aquellas que hacen emanar dicho poder de la legalidad, como rasgo propio del Estado de derecho. Progresivamente, como señala este autor, el Estado va absorbiendo los potenciales focos de conflicto resistente mediante la institucionalización de una serie de remedios contra la tiranía. 
Frente a la tiranía, situación paradigmática de abuso de poder y deslegitimación, estos instrumentos permitirán a los súbditos y posteriormente ciudadanos deponer más o menos pacíficamente a los malos gobernantes mediante acciones distintas al cambio revolucionario o a los actos violentos de sedición. El desarrollo de estos instrumentos legales incluye primeramente la consagración de los principios de legalidad y legitimidad como inherentes al ejercicio del poder, él mismo sometido a ambos, y se despliega posteriormente mediante una constitucionalización del juego de oposición parlamentaria y de la representación popular, que somete al gobernante al escrutinio periódico a través de elecciones.

Pese al desarrollo de todos estos dispositivos, ha subsistido hasta nuestros días el problema de qué hacer con todas aquellas formas de oposición extralegal "extralegal" respecto a las normas a las que se oponen-y deslegitimadora. Y parece que seguirá subsistiendo, porque el principio de legalidad no excluye totalmente ni de modo definitivo la posibilidad de la existencia de normas injustas o que acaban por devenir fuentes de injusticia. El carácter irresoluble de esta situación, que atañe no tanto a una colisión con el poder como a la articulación de la ley (más adelante veremos si esta condición abierta es realmente un problema o no), nos obliga a tener que pasar, volis nolis, en nuestro tratamiento de la protesta por el reto de la noción de desobediencia civil. Un desafío del cual no puede escapar ningún pensador constitucionalista, puesto que en ella se pone en juego una determinada interpretación de cómo se fundamentan e interpretan los principios constitucionales.

Tampoco aquí es posible realizar una reconstrucción extensa del gran número de pensadores y pensadoras que han acometido esta tarea, pero es posible señalar, a partir de la selección de algunos especialmente significativos (Arendt, Rawls, Habermas, Bobbio), una serie de aspectos que tendencialmente permiten ponerlos en relación. Todos ellos, en diferentes grados y con distintos énfasis, entienden la necesidad de concebir la desobediencia civil en diálogo con los principios constitucionales y no como un mero intento de disolver o destruir el sistema legal. En todo momento, no obstante, parece que la violencia en estas acciones es lo que señala una frontera de justificabilidad, aunque esta demarcación nunca termine de quedar inequívocamente trazada, dada la multiplicidad e indeterminación de lo que se puede interpretar como "acto violento"

En cualquier caso, es importante destacar de modo general que todos estos autores proponen conceptualizar la desobediencia civil como algo que se sitúa ante la ley y no sólo contra la misma. Para ello, coinciden en deslindar la desobediencia civil del mero desacatamiento a título individual o colectivo, así como en concederle una dimensión simbólico-significativa y unas condiciones para que sea un acto con sentido político. Este sentido político procedería situarlo, como hemos dicho, ante la ley, en este caso el ordenamiento constitucional y no solo frente a los códigos penales. En otras palabras, situar la desobediencia civil más allá del problema de la transgresión normativa para emplazarla en el terreno de la política.

La autora que quizás ha insistido de modo más enfático en esta interpretación específicamente política de la desobediencia civil es Hannah Arendt (1998) en su célebre ensayo "Desobediencia civil". Para Arendt, es preciso comprender la potencia y alcance de la desobediencia civil en la vida política frente a otras formas de desacato, caracterizadas por la pura transgresión, como es el caso del criminal o por la opción moral individual en el caso de la objeción de conciencia. Si las minorías disidentes que se expresan a través de la desobediencia civil tienen un papel político constitucional que es compatible con el espíritu de las leyes, no es menos cierto que resulta extremadamente dificultoso incorporar este fenómeno a la cultura legal, pues falta todavía el lenguaje y la política específicos para ello: "Tal vez se precise una 
situación de emergencia antes de que podamos hallar un lenguaje cómodo para la desobediencia civil no sólo en nuestro lenguaje sino también en nuestro sistema político" (Arendt, 1998: 108) En todo caso, para la pensadora alemana cualquier comunidad se vuelve despótica cuando se reprime el derecho de disentir, pues la posibilidad de desobediencia no es ni marginal ni disfuncional sino que es la dimensión estructuralmente constitutiva del consenso. El consenso sólo es posible cuando es voluntario, o sea, cuando existe la posibilidad efectiva de disentir.

Precisamente por este carácter plural y de autonomía restringida y coordinada, que retiene el vínculo mantenido en la comunidad política, la relación con las instituciones políticas no es coactiva sino representativa y la obligación del ciudadano para con la ley excede una mera interpretación en términos de moral individual, para entrar en una dimensión de identificación que sirve de base a una concepción del poder político como poder común. Para la pensadora, el disentimiento presente en la desobediencia civil no es un conflicto individual de conciencias frente a la ley, ni se trata de un enfrentamiento meramente personal con la estructura normativa, sino que es algo de naturaleza política. Por esta razón no puede ser adecuadamente comprendido ni justamente juzgado si nos limitamos a una relación particular del ciudadano con la ley, que constituye "un extraño y no siempre feliz matrimonio teórico, de la moralidad y de la legalidad, de la conciencia y de la ley" (Arendt, 1998: 60).

Desde este punto de vista, la desobediencia civil, que es una acción colectiva llevada a cabo por una minoría, es un instrumento político de primera magnitud frente a las distorsiones y límites de la regla de mayorías. Por eso, frente a un enfoque exclusivamente penal de la desobediencia, Arendt insta a los tribunales a que reconozcan un enfoque político a la hora de juzgar este tipo de acciones. La desobediencia civil entendida como potencial de renovación institucional es expresión de la capacidad común de asociación desde el disentimiento que es constitutiva de una comunidad política libre y la respuesta gubernamental ante ella no puede quedar confinada sólo al plano jurídico. Ha de ser resueltamente política.

Una interpretación igualmente política de la desobediencia civil la encontramos en el que quizás ha sido el abordaje sobre este fenómeno con el que mayor número de interpretaciones posteriores se han tenido que medir o han tenido que desafiar, nos referimos al de John Rawls en Una teoría de la justicia (1971). Como es sabido, y plenamente representativo del procedimiento habitual de exposición rawlsiano, el pensador comienza con una restricción del terreno donde propondrá su definición tentativa de desobediencia civil. Tal como afirma, su teoría no es un planteamiento general sino que se circunscribe al caso especial de sociedades casi justas, esto es, sociedades bien ordenadas en las que se producen sin embargo injusticias, "un Estado cercano al ideal de justicia" que entiende que debe ser un Estado democrático. Por ello su teoría trata sobre "la función y conveniencia de la desobediencia civil frente a la autoridad democrática legítimamente establecida, no es aplicable a otras formas de gobierno y salvo de modo accidental, tampoco a otras clases de disidencia o resistencia" (Rawls, 1991: 319).

Rawls es plenamente consciente de la importancia de no renunciar a los principios liberales en la concepción de un sistema constitucional bajo el imperativo de legalidad, fundamentos que priorizan la aceptación del marco constitucional por razones de principio y no sólo de prudencia u obligación. Por esta razón, su aproximación a la desobediencia civil se construye desde la perspectiva de un conflicto de deberes que se le plantea al ciudadano: en qué punto deja de ser irrevocable el imperativo de legalidad en razón del derecho a defender las propias libertades. Evidentemente esto debe entrañar, también aquí, el problema de la 
naturaleza y límites de las mayorías. Para Rawls el problema consiste en justificar este caso excepcional sin el cual fallaría el "fundamento moral" -para entendernos, de legitimidad- de la democracia desde un punto de vista liberal. De lo que se trata es de poder justificar esta acción ilegal en un marco constitucional, y para ello establece una definición de la desobediencia que incluye unas condiciones de justificación destinadas a ofrecer el marco para dicha inteligibilidad constitucional frente a otras formas de contestación: "Debo empezar por definir la desobediencia civil como un acto ilegal público, no violento, de conciencia pero de carácter político, realizado habitualmente con el fin de provocar un cambio en la legislación o en la política gubernamental" (Rawls, 1991: 320)

En su propósito de interpelar públicamente el sentido de la justicia de la mayoría de la sociedad, quienes desobedecen muestran una comprensión de los fundamentos morales de la democracia, a los cuales apelan para dar sentido a su acción y se comprometen asimismo a responder de las consecuencias de su acto. Por ello Rawls considera que puede ser un instrumento, aunque ciertamente ilegal, de estabilización de un sistema constitucional, al informar de sus fallos y proporcionar correctivos en la forma de alternativas presentadas a la consideración de sus conciudadanos. Eso sí, Rawls no escribe en ningún momento de una forma entusiasta sobre la desobediencia civil, acerca de la cual aconseja "no esperar demasiado" pese a su prometedor carácter de resistencia a la injusticia y a la que en todo caso aplica una clausula prudencial al especificar en varios momentos que debe ser utilizada con la debida mesura. Queda sin embargo en suspenso el problema de que para juzgar la justificabilidad de esas acciones en el esquema rawlsiano se establecen las condiciones antes de los hechos y no después, con lo cual lo que en realidad aparece para crear nuevos criterios paradójicamente se ve constreñido por criterios previos a dicha aparición, criterios necesarios para su reconocimiento como acción normativamente significativa.

Este último problema es quizás mucho más profundizado en la contribución de Habermas a la cuestión de la desobediencia civil, al entroncar con su aguda reflexión sobre los problemas de validez en el ámbito normativo, problemas que trascienden la facticidad de los distintos ordenamientos jurídicos.

A diferencia de Rawls, y aunque coincida en gran medida con varios de los supuestos establecidos por éste, Habermas sí que realiza una defensa mucho más enfática de la desobediencia civil en el ensayo que dedica a la misma calificándola, parafraseando a Rawls, de "piedra de toque del Estado democrático de derecho" (Habermas, 1997). En el momento en el que escribe este ensayo el pensador se sitúa en el marco de una polémica acerca del endurecimiento penal de la regulación del derecho de manifestación en su país, y su reacción se recorta contra la ampliación, a su juicio excesiva, que estaba teniendo lugar en Alemania del concepto jurídico de violencia aplicado a estas acciones. Para Habermas, la desobediencia civil constituye una "forma no convencional de formulación de la voluntad política" (Habermas, 1997: 54) que debe considerarse un elemento central de una cultura política madura: "Todo Estado democrático de derecho que está seguro de sí mismo considera que la desobediencia civil es una parte componente normal de su cultura política, precisamente porque es necesaria" (Habermas, 1997: 54) No obstante, al igual que Rawls, entiende que la identificación con los fundamentos constitucionales es condición necesaria para que, incluso cuando traspase los límites de lo jurídicamente lícito, una acción de protesta tenga un sentido político.

Pero Habermas no sólo establece condiciones a los gobernados, ex parte principis, en la forma de esta invocación o referencia obligatoria de la acción a los principios constitucionales, sino que también plantea requisitos o peticiones a la parte 
de los gobernantes, desde el punto de vista del populus. Se les requiere la aceptación de esta forma de discrepancia bajo condiciones similares señaladas por Rawls, como un procedimiento necesario para la autocorrección de los sistemas legales en virtud de la tensión que todos ellos contienen entre los momentos internos de legitimidad y legalidad. En el trasfondo de la perspectiva habermasiana hay una reacción a la utilización tautológica del principio de legalidad para reprimir la desobediencia civil ("la ley es la ley"), un uso que llega a calificar como "autoritario-legalista". Para Habermas, la obligación de obediencia tiene que partir de "un reconocimiento reflexivo y por tanto voluntario de aquella aspiración normativa a la justicia que late en todo ordenamiento jurídico" (Habermas, 1997: 55) La norma, desde este punto de vista, no sólo es legal sino que también ha de ser reconocida como legítima, en virtud de una legitimación procedimental derivada de un proceso de debate, aprobación y promulgación por los órganos competentes designados constitucionalmente a este efecto. Ahora bien, según señala Habermas, esta legitimación procedimental legitima las normas, pero nada dice de cómo se legitima la totalidad del procedimiento legitimador. Para contestar a esta pregunta es preciso apelar a otro nivel, el de la validez de las normas. De ahí la necesidad de considerar la relación dialéctica entre la legitimidad y la legalidad, a partir de la observación de que una constitución no sólo rige desde el punto de vista legal, sino que además debe convencer a sus ciudadanos si quiere representar realmente su voluntad. Para ello, según señala Habermas, "la Constitución ha de justificarse en virtud de unos principios cuya validez no puede depender de que el derecho positivo coincida con ella o no. Por este motivo, el Estado constitucional moderno sólo puede esperar la obediencia de sus ciudadanos a la ley si, y en la medida en que, se apoya sobre principios dignos de reconocimiento a cuya luz, pues, pueda justificarse como legítimo lo que es legal o, en su caso, pueda comprobarse como ilegítimo" (Habermas, 1997: 58)

Se adivinará lo espinoso de la cuestión que propone Habermas, pues es ni más ni menos que la posibilidad de que haya lo que desde una perspectiva exclusivamente legal parecería un oxímoron: legalidades ilegítimas. Si el pensador puede adoptar esta perspectiva es porque, como él mismo se encarga de explicitar al inicio de su ensayo, aborda la cuestión de la desobediencia civil desde una aproximación iusfilosófica y no jurídico positiva. Esto le permite analizar la posibilidad de que se produzca tensión entre la legalidad y la legitimidad. En este nivel de reflexión, las normas fundamentales constitucionales han de fundamentarse en algo más que el derecho positivo y lo hacen sobre la base de su universalización, que es posible sólo en virtud de su capacidad de representar intereses generalizables. Solo así pueden generar aceptación y no sólo acatamiento por parte de quienes se vinculan a ellas:

\footnotetext{
"únicamente pueden justificarse aquellas normas que expresan un interés susceptible de ser generalizado y que, en consecuencia, contaría con la aprobación voluntaria de todos los afectados. Por ello, esta aprobación aparece vinculada a un procedimiento de formación racional de la voluntad; por ello, también, esta forma de fundamentación excluye el recurso, hoy de moda, a un orden axiológico material experimentado históricamente" (Habermas, 1997: 58).
}

De ahí que "el Estado democrático de derecho, al no fundamentar su legitimidad sobre la pura legalidad, no puede exigir de sus ciudadanos una obediencia jurídica incondicional, sino una cualificada" (Habermas, 1997: 58) En otras palabras, lo que Habermas está sosteniendo es la idea de una falibilidad normativa, que abre la puerta a que la desobediencia civil pueda justificarse desde situaciones en las que la obediencia a normas ilegítimas se haga insostenible, forzando a una revisión de por qué estas normas han fallado, es decir, a una renovación normativa razonada que dota de sentido y comunicabilidad a la acción transgresora. A esto lo denomina 
Habermas "desconfianza" y a su juicio juega un papel central e ineludible en el Estado de derecho. Con el fin de alcanzar estabilidad, y no de desestabilizarse como pudiera parecer, el Estado de derecho debe mantener esta desconfianza ante la posibilidad de "una injusticia que puede manifestarse en formas legales" -aunque Habermas reconoce que esta actitud no puede solidificar en una forma institucionalmente segura. A semejante suplementación por la que el Estado de derecho adoptaría la paradójica tarea de ser vigilante de sí mismo, Habermas le concede un peso incluso mayor de algunos de los mecanismos de control institucionalizados:

"Con esta idea de una desconfianza de sí mismo no institucionalizada, el Estado de derecho trasciende incluso el conjunto de sus propios ordenamientos positivos. Esta paradoja encuentra su solución en una cultura política que reconoce u otorga a las ciudadanas y ciudadanos la sensibilidad, la capacidad de raciocinio y la disposición a aceptar riesgos necesarios que son imprescindibles en situación de transición y de excepción para reconocer las violaciones legales de la legitimidad y, llegado el caso, para actuar ilegalmente por convicción moral". (Habermas, 1997: 59)

Es importante notar que Habermas no habla en el párrafo citado de mera resistencia a la norma sino de desobediencia civil. Ello es así porque la desobediencia civil requiere de una cultura política que da por cierto que sus ciudadanos poseen capacidad para identificar estas situaciones límites de ilegitimidad y actuar en consecuencia, si bien no deben hacerlo en función de preferencias espurias ni por convicciones puramente dogmáticas. Pero a la vez, y esto es importante, semejante cultura política crítica no sería posible si no se supusiera que estos mismos ciudadanos "reconocen la legalidad democrática del orden imperante" (Habermas, 1997: 60) En otras palabras, los ciudadanos se sitúan ante el imperio de la ley, interpelándolo y no simplemente fuera del mismo o contra él. Podríamos decir que pretenden, en otras palabras, realizar un acto comunicativo. $Y$ un acto de habla con un resultado feliz implica y requiere una respuesta por ambas partes.

\section{Protesta y democracia}

Precisamente esta capacidad de respuesta, que se efectúa al establecerse una comunicación entre las partes implicadas, es lo que carga de valor democrático a estos fenómenos de discrepancia a primera vista tan inseguros y problemáticos y lo que les dota de un potencial corrector y constructivo políticamente interesante. Como vamos a ver, tanto Habermas como Bobbio insisten justo en este aspecto de interpelación mutua. Una interpelación tal que -esto es importante dejarlo claro- lejos de conducir a la destrucción del orden legal lo fortalecería, al dotarlo de la capacidad de dirigirse y escuchar a los ciudadanos y aprovechar esta información para su propio perfeccionamiento. Una competencia comunicativa que, además de útil, es fuente primordial de la legitimidad tal como la concibe Habermas, producto de la convicción y asentimiento y no sólo de la obediencia a la legalidad.

En el tratamiento que realiza Norberto Bobbio de la cuestión de la resistencia en el marco de una teoría general de la política se encuentra una distinción muy útil para enfatizar este aspecto comunicativo del que hemos pasado a ocuparnos. Bobbio diferencia entre "contestación" y "resistencia", pese a que ambas constituyen formas de oposición extralegal, con el fin de poner de relieve dos problemas: la cuestión de si se pone en peligro o no el sistema legal al completo (si se pretende deslegitimar una norma o el conjunto normativo como tal) y la cuestión del valor específico que aporta a la cultura política democrática la oposición extralegal. Con el fin de ajustar mejor la diferencia entre resistencia y contestación, Bobbio recurre aristotélicamente- a contraponer cada uno de estos términos con su contrario, a fin de poder presentar mejor la oposición formada por ambos. El contrario de la 
resistencia es la obediencia, mientras que el de la contestación es la aceptación. De este modo se iluminan matices fundamentales que permiten entender que no es lo mismo resistir que contestar, la relación de oposición que mantienen. Así, la resistencia queda elucidada como "cualquier comportamiento de ruptura frente al orden constituido, que pone en crisis al sistema por su sola producción, como sucede en un tumulto (...) Lo pone en crisis pero no necesariamente lo cuestiona" (Bobbio, 2005: 277). La contestación, en cambio, "se refiere más que a un comportamiento de ruptura a una actitud de crítica que pone en cuestión el orden constituido, sin ponerlo necesariamente en crisis" (Bobbio, 2005: 277). Ahora se aprecia mejor el valor de esta distinción para nuestros propósitos, puesto que lo que Bobbio proporciona con ella es la posibilidad de entender, obviamente si hay voluntad política para ello, que la acción de la desobediencia civil no es una acción muda sino elocuente, que no se agota en el momento de la transgresión sino que desencadena un discurso crítico y un debate público.

Este es un valor similar al defendido por Habermas al considerar a la desobediencia civil como un mecanismo de ensayo y error, un laboratorio de experiencia política que construye -y no destruye- el marco legal, y que es prueba de que los avances constitucionales no son procesos que discurren históricamente en línea recta sino a través de errores, resistencias y conflicto. Para Habermas, el que el Estado de derecho esté provisto de una multitud de mecanismos dentro de la legalidad para dar respuesta a estos puntos de fricción no significa que haya que eliminar la consideración de otros mecanismos posibles fuera de la legalidad. De hecho es más bien su prueba, ya que muestra que todos ellos son falibles y perfeccionables. De este modo, concluye Habermas, "son experimentos moralmente justificados sin los cuales una república viva no puede conservar su capacidad de innovación ni la creencia de sus ciudadanos en su legitimidad" (Habermas, 1997: 61) Lejos de ser excepción, la existencia de estas tensiones entre legalidad y legitimidad es un caso normal que se producirá siempre, piensa Habermas. $Y$ dado que la desobediencia civil así considerada no pone en cuestión el conjunto del ordenamiento jurídico como tal, el Estado tiene que prescindir de la tentación de usar contra ella todo su poder punitivo. Esto tampoco quiere decir que se normalice la desobediencia civil como comportamiento generalizado sin responsabilidades ni consecuencias, puesto que sería una situación insostenible. Lo que hace Habermas es un llamamiento a la autocontención de ambas partes, ciudadanos y Estado. El problema surge cuando un Estado de derecho persigue la desobediencia civil como si fuera un delito común, puesto que esto lo sitúa, a juicio del pensador alemán, en la pendiente resbaladiza de un legalismo autoritario (Habermas, 1997: 70) del que nos ocuparemos en último lugar.

\section{Castigo o diálogo. Consideraciones finales}

Hasta aquí hemos reconstruido la manera en la que diversos autores desplazan la cuestión de la protesta desde la estrecha perspectiva de la transgresión legal a un marco político más amplio, analizando la función y papel democrático de la misma. La protesta se entiende así como un instrumento para extender el alcance y profundidad de la forma democrática. Es hora de concluir pero antes hay que apuntar hacia el proceso inverso de esta voluntad expansiva democrática, esto es, hacia la involución democrática que tiene lugar cuando se interrumpe este circuito de comunicación entre gobernantes y gobernados, entre el orden legal y sus posibles contestaciones. La dinámica político-jurídica se escora entonces hacia la vía punitiva, con el consiguiente menoscabo de la necesaria legitimidad sobre la que se sostienen los siempre frágiles equilibrios democráticos. En suma, cuando no se cultiva un uso dialógico y comunicativo de la legalidad entramos en un enfoque penal monológico y meramente represivo. Con ello se dificulta que la toma de decisiones democrática 
tenga un carácter inclusivo, al expulsar a los grupos disidentes al limbo de la extralegalidad.

Para evitar este escoramiento hacia el castigo y la exclusión autores como Gargarella (2014) apuntan a la necesidad de adoptar un enfoque comunicativo o dialógico en el derecho penal aplicable en los casos de protesta. En este enfoque "el proceso penal se considera como si tuviera dos vías: Una parte trata de dirigirse activamente a la otra, recurriendo a su razón, en lugar de a su miedo" ( Gargarella, 2014: 14). Este parece ser el único enfoque penal compatible con las condiciones de una democracia deliberativa máximamente inclusiva, pues de otro modo se transforma la cuestión social en una cuestión punitiva. De prevalecer esta estrecha aproximación a la conflictividad social, muchos de los problemas que se adivinan en el horizonte próximo de sociedades conflictivas, desigualitarias y empobrecidas no solo no se resolverán, sino que se agravarán por un uso represivo de las leyes penales. Figuras como Luigi Ferrajoli, en su ensayo "Democracia y miedo", han advertido de una preocupante tendencia hacia el populismo punitivo en las sociedades contemporáneas, en las que diagnostica un "uso demagógico del derecho penal, tendente a reflejar y a alimentar el miedo como fuente de consenso electoral mediante políticas y medidas antiliberales, indiferentes por un lado a las causas estructurales de los fenómenos criminales e ineficaces para su prevención" (Ferrajoli, 2014: 99)

Este paradigma de conversación racional que hemos descrito en el plano penal presenta no obstante limitaciones en el plano político, estando lejos de ser una panacea. Se puede dar el caso de que quienes deberían ser invitados a esta conversación no cuenten, como señalábamos al principio, con los recursos comunicativos y la agencia política necesarios para participar en tal "intercambio de razones". Entonces es preciso ir más allá de la democracia deliberativa, en la dirección de un movimiento de democratización de la propia comunicación, tal como reivindica Iris Marion Young (2000). La autora insta a abrir el modelo de comunicación deliberativa a formas expresivas distintas a las caracterizadas usualmente por este paradigma, entre las que podrían mencionarse muchas acciones actuales de protesta que no hacen uso de las reglas de argumentación habituales. Evitando esta exclusión, favoreciendo esta escucha, se prevendría que el mismo paradigma que se presenta como la forma de solución más razonable a los conflictos sociales (la democracia deliberativa) termine por convertirse en fuente de discriminación.

$\mathrm{Si}$, como parece, en la actualidad no estamos avanzando demasiado en la dirección de sociedades bien ordenadas y regidas por una idea de justicia como establecía Rawls para su idea de la desobediencia civil, sino más bien hacia su contrario, la protesta está llamada a constituir un mecanismo aún más fundamental de expresión política y de corrección de esas tendencias corrosivas y deslegitimadoras de nuestros órdenes de convivencia. Es preciso desarrollar los instrumentos y la sensibilidad apropiados para una escucha atenta de lo que necesiten decirnos las voces de la protesta, porque ello supondrá construir cultura legal y política en vez de destruirla.

\section{Bibliografía}

ARENDT, H. (1997), Crisis de la república, Taurus, Madrid.

BOBBIO, N. (1991), "Desobediencia civil". En: BOBBIO, N., PASQUINO, G. et alii, Diccionario de política, México, Siglo XXI, pp. 477-482.

BOBBIO, N. (2005) Teoría general de la política, Trotta, Madrid. 
FERRAJOLI, L. (2014), “Democracia y miedo". En: BOVERO, M. y PAZÉ, V. (eds.), La democracia en nueve lecciones, Madrid, Trotta, pp.99-113.

GARCÍA RUIZ, A. (2013), La gobernanza del miedo, Proteus, Barcelona.

GARGARELLA R. (2014), "Expandiendo la democracia. Democracia y derecho penal: el caso de las protestas sociales". En: Gargarella, R., Susin, R. et alii Democracia y protesta, Zaragoza, Sibirana Ediciones, pp. 6-44.

GARGARELLA, R. (2005), El derecho a la protesta. El primer derecho, AdHoc, Buenos Aires.

HABERMAS, J. (1997), "La desobediencia civil, piedra de toque del Estado democrático de derecho". En: HABERMAS, J, Ensayos Políticos, Barcelona, Península, pp. 51-71.

HONIG, B. (1993), Political Theory and the Displacement of Politics, Cornell University Press, Ithaca NY.

RAWLS, J. (1991), A Theory of Justice, Harvard University Press, Cambridge.

RORTY, R. (2001), La filosofía y el espejo de la naturaleza, Cátedra, Madrid.

SELLARS, W. (1997), Empiricism and the Philosophy of Mind, Harvard University Press, Cambridge.

SHKLAR, J. (2010), Los rostros de la injusticia, Herder, Barcelona.

YOUNG, I. M. (2000), "La democracia y "el Otro": más allá de la democracia deliberativa", Revista Jurídica de la Universidad de Palermo, Año 5, N.1, Palermo, pp. 41-56.

YOUNG, I. M. (2000), Inclusion and democracy, Oxford University Press, Oxford. 